\title{
Dominant Time Scales of Potentially Predictable Precipitation Variations across the Continental United States $\mathscr{O}$
}

\author{
Bruce T. Anderson, Dan J. S. Gianotti, AND Guido SAlvucci \\ Department of Earth and Environment, Boston University, Boston, Massachusetts \\ JASON FURTADO \\ School of Meteorology, University of Oklahoma, Norman, Oklahoma
}

(Manuscript received 25 August 2015, in final form 19 May 2016)

\begin{abstract}
While low-frequency variations in precipitation amount, occurrence counts (hereafter "occurrence"), and intensity can take place on seasonal to multidecadal time scales, it is often unclear at which time scales these precipitation variations can be ascribed to potentially predictable, climate-induced changes versus simple, stochastic (i.e., random) precipitation event evolutions. This paper seeks to isolate the dominant time scales at which potentially predictable changes in observed precipitation characteristics occur over the continental United States and analyze sources of revealed potentially predictable precipitation variations for particular regions. The results highlight that at interannual time scales (here defined as those shorter than 7 years), the potential for predicting annual precipitation amounts tends to be higher than for annual event occurrence or intensity, with interannual potential predictability highest in both relatively dry and wet locations and lowest in transition regions. By contrast, at time scales greater than 7 years the potential for predicting annual event occurrence tends to be higher than amount or intensity, with $>20$-yr time scale potential predictability highest in relatively wet locations and lowest in relatively dry locations. To highlight the utility of this type of analysis, two robust signals are selected for further investigation, including 1) approximately 10 -yr time scale variations in potentially predictable annual amounts over the northwestern United States and 2) 20-60-yr time scale variations in potentially predictable annual event occurrence over the southwestern United States. While mechanistic drivers for these observed variations are still being investigated, concurrent and precursor climate-state estimates in the atmosphere and ocean-principally over the Pacific sector-are provided, the monitoring of which may help realize the potential for predicting precipitation variations in these regions.
\end{abstract}

\section{Introduction}

It is widely recognized that there is utility in quantifying the potential predictability (PP) of seasonal to multidecadal variations in precipitation, which can be (qualitatively) thought of as that fraction of precipitation variance that remains once inherently unpredictable variance associated with stochastically generated noise has been removed (e.g., Leith 1978; Madden and Shea 1978). For instance, such

Supplemental information related to this paper is available at the Journals Online website: http://dx.doi.org/10.1175/ JCLI-D-15-0635.s1.

Corresponding author address: Bruce T. Anderson, Earth and Environment, Boston University, 685 Commonwealth Ave., Rm. 130, Boston, MA 02215.

E-mail: brucea@bu.edu estimates allow us to identify "hot spot" regions where the potential for making skillful climate forecasts is highest, as well as "cold spot" regions where climate noise dominates any signal. Further, these estimates can help guide investigations into the role that various climatic phenomena [such as evolving oceanic and atmospheric states, preceding soil moisture and snow cover conditions, and/or human-induced forcing (e.g., Ropelewski and Halpert 1986; Allen and Ingram 2002; Koster et al. 2004; Stevenson et al. 2015; Tuttle and Salvucci 2016)] versus stochastic, meteorological processes (e.g., generated by typical weather events) play in modifying regional precipitation on various time scales. Finally, they can help provide guidance as to where and when the issuance of climate forecasts may be most reasonable.

Given this recognition, numerous methods have been developed to estimate PP from numerical model output and observations. Here we provide only a brief summary 
of these methods; reviews of the theoretical and methodological basis for them can be found in Collins (2002), Smith et al. (2012), and Gianotti et al. (2013). As an example, one set of methods uses "perfect" numerical model simulations in which a coupled oceanatmosphere model or atmosphere-only model is run once to generate the "observed" state and is then run multiple other times to generate the "forecasted" states. Comparison of these observed and forecasted states can be used to determine the signal-to-noise ratio as well as other metrics for characterizing the potential predictability of precipitation variations across regions (e.g., Rowell 1998; Boer 2000; Collins 2002; Moron et al. 2006; Boer and Lambert 2008; Schubert et al. 2008; Becker et al. 2013). Alternatively, estimates of stochastically generated interannual to multidecadal time scale variance can be derived from daily time series of observed data via their power spectra across all years, at which point the potentially predictable fraction of observed precipitation variance can be derived as a residual of the total and stochastically generated values (Madden 1976; Madden and Shea 1978). While this method is appropriate for smoothly varying, normally distributed fields such as sea level pressure (Madden 1976) and temperature (Madden and Shea 1978), it may not be appropriate for precipitation (e.g., Zheng et al. 2000). In these cases, the stochastically generated interannual to multidecadal time scale variance can still be estimated from observed data in conjunction with various "weather generator" models (e.g., Singh and Kripalani 1986; Shea and Madden 1990; Gregory et al. 1993; Katz and Parlange 1998; Wang et al. 2006, 2007), also referred to as stationary stochastic weather models (SSWMs; Gianotti et al. 2014). The potentially predictable variance within the observed data is then defined as that which lies outside the envelope of variance produced solely from stochastic, short-memory meteorological processes, as determined by the observationally constrained SSWM.

Importantly, analyses such as these have shown that the potential for predicting precipitation variations in a given region may be time scale dependent; that is, the fraction of predictable variance need not be the same at seasonal, interannual, decadal, or longer time scales (Boer 2004; Jia and DelSole 2012; Hoskins 2013; Goddard et al. 2013). While most studies of time scaledependent PP estimates have relied on use of numerical model data, it is possible that these numerical modelbased estimates can both under- and overestimate observed PP (Eade et al. 2014). For that reason, in this study we will attempt to perform a similar analysis using observationally constrained PP estimates derived from SSWMs, with a focus on the continental United States.
While it may be tempting to try to perform a comparison of the observationally constrained estimates of time scale-dependent PP and those provided by numerical model results, a truly quantitative comparison requires first constructing model-based SSWMs for each grid point within the United States, then using the stochastically generated daily precipitation data from the model-specific SSWMs to quantify the amount of inherent, model-based variability that is potentially predictable at various time scales. Unfortunately, the development of a generalizable SSWM framework that can be applied both to station- and model-based data has been elusive. As such, here we simply present the results derived from observations.

The data and statistical methods employed to identify the dominant time scales of potentially predictable precipitation variations across the United States are first discussed in section 2. Section 3 then provides a spatial and temporal disaggregation of potentially predictable precipitation variations across the United States, along with an analysis of particularly robust signals over the southwestern and northwestern United States. A summary of the results is then presented, followed by a short discussion of the implications for long-range climate forecasts.

\section{Data and methods}

\section{a. Data}

As in previous work (Gianotti et al. 2013; Pal et al. 2013; Gianotti et al. 2014; Anderson et al. 2015a), we use serially complete daily precipitation data compiled from the quality-controlled National Climatic Data Center (NCDC) Summary of the Day (Reek et al. 1992) by the U.S. Historical Climatology Network (USHCN; Williams et al. 2006). From the approximately 1200 available station records, we subselect those that have data that extend through 31 December 2009 , are at least 80 years in length, and have fewer than $5 \%$ missing values. Our analysis is based upon these 774 stations, all of which span 80-110 years and start from 1930 and earlier.

Observationally constrained atmospheric fields are taken from version 2 of the Twentieth Century Reanalysis (20CRv2; Compo et al. 2011). This long-term reanalysis contains data from 1871 to 2012 globally on a $2^{\circ} \times 2^{\circ}$ longitude/latitude grid and on 24 pressure levels ranging nonuniformly from 1000 to $10 \mathrm{hPa}$. Principal fields considered include geopotential heights, sea level pressure, winds, and air temperature. Seasonal- and annual-mean fields are considered in this work, with anomalies derived by removing the long-term climatological 
mean from the monthly values at each grid point and then averaging over the respective seasons or years.

\section{b. Precipitation metrics}

For this analysis we will focus on detecting potentially predictable variations in annual-mean precipitation characteristics, that is, mean total accumulation (TOT), mean event occurrence counts (hereafter "occurrence"; OCC), and mean event intensity [defined as the ratio of the accumulation to occurrence and equivalent to the Expert Team on Climate Change Detection and Indices' Simple Intensity Index (SII); Peterson et al. 2001]. For this study any daily accumulation of less than $1 \mathrm{~mm} \mathrm{day}^{-1}$ constitutes a "no precipitation" day, as recommended by Groisman and Knight (2008). Further, because the "water year" at a given station may not align with the calendar year, at each station we shift the individual daily precipitation time series such that the annual precipitation metrics-including the annual occurrence, intensity, and total accumulation values-are calculated for a 365-day window centered on the station's climatological wet season [see Anderson et al. (2015b) for details]. In addition, we will also analyze seasonal precipitation metrics calculated using uniform 91-day windows centered at various times of the year [again as in Anderson et al. (2015b)]. Potentially predictable variance estimates are subsequently estimated from the year-to-year changes in these annual and seasonal values (see next section).

\section{c. Calculation of potential predictability}

To quantify the $\mathrm{PP}$ of precipitation variance within a given observed data record, we first estimate the variance attributable to inherently unpredictable shortmemory meteorological processes using stationary stochastic weather models, which account for the occurrence and intensity characteristics of daily precipitation events and their short-term (e.g., 1-5 day) persistence (Katz 1977; Swift and Schreuder 1981; Wilks 1999). Full details of these SSWMs are provided in Gianotti et al. (2014). Briefly, the day-to-day variability of precipitation occurrence is represented using Markov chain models with seasonally varying transition probabilities and chain orders. A separate model is built for each day of the year by fitting it to the empirical data pooled across a given time window (centered on the given day) in order to improve robustness of the transition probability estimates. The size of the pooling window along with the chain order are objectively selected using the corrected Akaike information criterion (AICc; Hurvich and Tsai 1989), which optimizes both the model's fit and complexity. The day-today variability of precipitation intensity is represented using a highly flexible gamma-gamma probability distribution mixture model in which the weighting of the two gamma distributions along with the five parameters varies with the day of year and previous days' precipitation occurrence. As with the occurrence model, data are first pooled across a time window centered on the given day (in order to improve robustness of the parameter estimates), the size of the pooling window and chain order are again selected using AICc, and then the model is fit to the empirical data using maximum likelihood estimation.

Using a given station's variable-order and seasonally varying but annually stationary SSWM, 1000 Monte Carlo simulations of the 80-110-yr historical record for that station are then generated. To do so, the simulations are forward integrated a single day at a time with the probability of occurrence and the probability distribution for intensity determined by the SSWM for that day of year (and station) along with the current model state and its state over the last 0-5 days of simulated data (depending upon the chain order of the SSWM for that day). For each station, the simulation is time-stepped forward each day for 80-110 years (depending upon the record length of the observed data for that station); then the simulation procedure is repeated another 1000 times. Again, Gianotti et al. (2014) provide a fuller description of this procedure for the interested reader.

Given the observed and stochastically generated data, the PP [or equivalently the potentially predictable variance (PPV)] of a particular precipitation characteristic at a particular station can be defined as the fraction of the observed variance that remains once the variance arising from the stochastic evolution of typical meteorological processes has been subtracted out (e.g., Rowell 1998; Boer 2004):

$$
\mathrm{PP}(\text { var })=\frac{\sigma_{\mathrm{obs}}^{2}-\overline{\sigma_{\mathrm{sim}}^{2}}}{\sigma_{\mathrm{obs}}^{2}},
$$

where var is the variable of interest (i.e., mean precipitation amount, occurrence, or intensity), $\sigma_{\mathrm{obs}}^{2}$ is the observed year-to-year variance in the given variable across the $80+$-yr station record, $\sigma_{\text {sim }}^{2}$ is the stochastically simulated year-to-year variance in the given variable across an identical time window, and the overbar represents the mean of the 1000 stochastically simulated variance estimates.

Previous work (Pal et al. 2013; Gianotti et al. 2014; Anderson et al. 2015a) has analyzed overall PPV for various annual (and seasonal) precipitation means and extremes across the United States. Here our interest is in isolating the time scales over which that PPV occurs. Toward this end we make use of the fact that the year-to-year 
variance in a given variable can be decomposed into its spectral components via

$$
\sigma^{2}=\sum_{k} A\left(\omega_{k}\right)^{2} / 2
$$

where $A\left(\omega_{k}\right)$ represents the $k$ discrete spectral coefficients at frequencies $\omega_{k}$. Since this decomposition is generalizable for both the observed and stochastically simulated variances, we can substitute (2) into (1) where appropriate and rewrite (1) as

$$
\mathrm{PP}(\text { var })=\sum_{k} \frac{\left[A_{\mathrm{obs}}\left(\omega_{k}\right)^{2}-\overline{A_{\mathrm{sim}}\left(\omega_{k}\right)^{2}}\right]}{2 \sigma_{\mathrm{obs}}^{2}} .
$$

Finally, we can designate the contribution of variance at a particular frequency (and hence time scale) to the overall PP of a given variable as

$$
\operatorname{PP}\left(\operatorname{var}, \omega_{k}\right)=\frac{\left[A_{\mathrm{obs}}\left(\omega_{k}\right)^{2}-\overline{A_{\mathrm{sim}}\left(\omega_{k}\right)^{2}}\right]}{2 \sigma_{\mathrm{obs}}^{2}} .
$$

For this analysis, the power spectra are estimated using a multitaper method (Thomson 1982) applied to the linearly detrended time series (so as not to introduce artificial high-frequency power) of year-to-year variations in a given precipitation characteristic (at a given station). Note that after detrending $\sigma_{\text {obs }}^{2} \neq \sum_{k} A\left(\omega_{k}\right)^{2} / 2$ and hence $\mathrm{PP}($ var $) \neq \sum_{k} \mathrm{PP}\left(\right.$ var, $\left.\omega_{k}\right)$. However, we can capture the potentially predictable signal imparted by the secular trend using the residual variance between the full time series of year-to-year variations in a given precipitation characteristic and the linearly detrended time series via

$$
\sigma^{2}(\text { trend })=\sigma_{\text {full }}^{2}-\sum_{k} A\left(\omega_{k}\right)^{2} / 2 .
$$

Again, since this decomposition is generalizable for both the observed and stochastically simulated variances, we can substitute (5) into (1) where appropriate and determine the contribution of variance of the secular trend to the overall $\mathrm{PP}$ of a given variable as

$$
\mathrm{PP}(\text { var }, \text { trend })=\frac{\left[\sigma_{\mathrm{obs}}^{2}(\text { trend })-\overline{\sigma_{\text {sim }}(\text { trend })^{2}}\right]}{\sigma_{\mathrm{obs}}^{2}} .
$$

From (1), (4), and (6) it follows that $\mathrm{PP}(\mathrm{var})=$ $\sum_{k} \mathrm{PP}\left(\operatorname{var}, \omega_{k}\right)+\mathrm{PP}($ var, trend $)$.

\section{d. Significance testing}

Statistical significance of the observed PP estimates requires determining the probability distribution under the null condition defined by no PP. This distribution can be derived by substituting the observed record variance (i.e., $\sigma_{\text {obs }}^{2}$ ) in (1) with each of the 1000 stochastically simulated variances:

$$
\mathrm{PP}_{\text {sim }}(\operatorname{var}, n)=\frac{\sigma_{\text {sim }}^{2}(n)-\overline{\sigma_{\text {sim }}^{2}}}{\sigma_{\text {sim }}^{2}(n)},
$$

where $n$ designates a member of the ensemble. Again, we deconstruct the overall PP into its spectral and trend components via

$$
\begin{aligned}
\mathrm{PP}_{\text {sim }}\left(\operatorname{var}, n, \omega_{k}\right) & =\frac{\left[A_{\text {sim }}\left(n, \omega_{k}\right)^{2}-\overline{A_{\text {sim }}\left(\omega_{k}\right)^{2}}\right]}{2 \sigma_{\text {sim }}^{2}(n)} \text { and } \\
\mathrm{PP}_{\text {sim }}(\operatorname{var}, n, \text { trend }) & =\frac{\left[\sigma_{\text {sim }}^{2}(n, \text { trend })-\overline{\sigma_{\text {sim }}(\text { trend })^{2}}\right]}{\sigma_{\text {sim }}^{2}(n)} .
\end{aligned}
$$

The probability that the observed PP estimates at a particular frequency are generated from short-memory stochastic processes can then be derived from the cumulative distribution of these $n=1000 \mathrm{PP}_{\text {sim }}\left(\operatorname{var}, n, \omega_{k}\right)$ values. Similarly we can determine the probability that the observed PP estimate associated with the secular trend is generated stochastically using the $n=$ $1000 \mathrm{PP}_{\text {sim }}$ (var, $n$, trend) values. Here we choose a directional $p<0.10$ threshold such that only observed PP estimates that lie above the 90th percentile of the stochastically generated distribution are considered to be significantly different from zero. Similarly, the significance of other empirical values can be tested by applying the relevant analysis to the stochastically simulated data in order to estimate the stochastically generated distribution of values, from which either a directional or nondirectional $p<0.10$ threshold is determined (as appropriate). For presentation purposes, in many cases we subsequently normalize the observed PPV values by the $p<0.10$ value in order to account for the unequal size of the frequency bins; see the appendix for information on how this normalization is performed, as well as how to convert the normalized PPV value (for a given characteristic or frequency bin) back to its nonnormalized PPV value.

\section{Results}

\section{a. Potential predictability of annual precipitation characteristics}

Since previous research has shown that the occurrence of precipitation is one of the leading potentially predictable precipitation characteristics (Gianotti et al. 2014), we start by investigating the potential to predict changes in annual precipitation occurrence at different 
OCC Norm. Pot. Pred.: 2-7yr

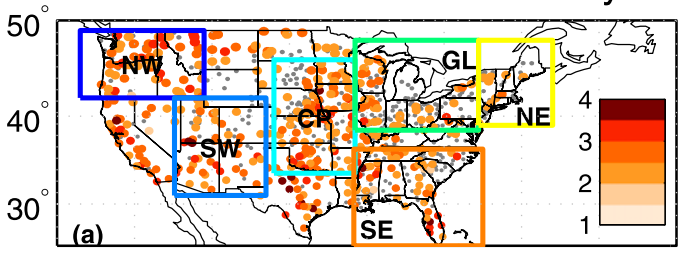

OCC Norm. Pot. Pred.: 20-40yr

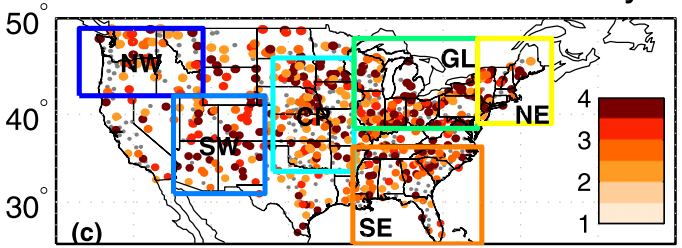

OCC Norm. Pot. Pred.: Trend

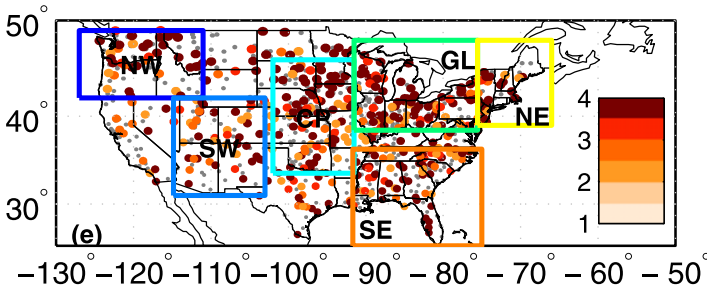

OCC Norm. Pot. Pred.: 7-20yr

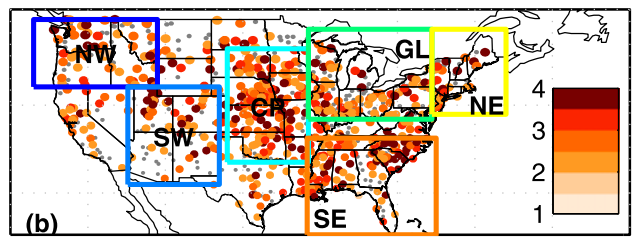

OCC Norm. Pot. Pred.: >40yr

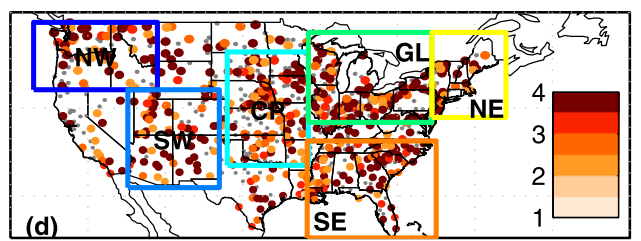

Regional Pot. Pred.: OCC

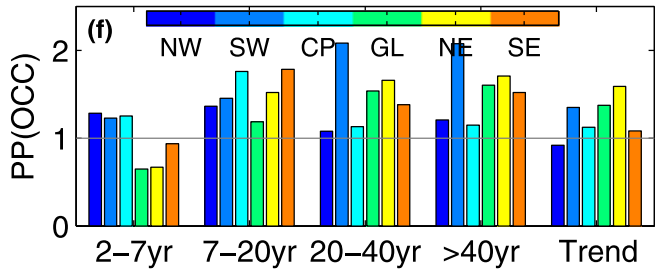

FIG. 1. Fraction of variance of a station's annual precipitation occurrence $\left(\mathrm{OCC} ; \mathrm{yr}^{-1}\right)$ within a given frequency bin that is potentially predictable, as derived from Eq. (3) and normalized by the 90th percentile threshold $(p<0.10)$ value derived from stochastically generated records for that station; see the appendix and Figs. S1-S3 in the supplemental material for normalization procedure and the conversion factors appropriate for calculating the nonnormalized values for a given characteristic/frequency bin. Values (unitless) range from 1 to 4 and are given by the color bar on the rhs; normalized magnitudes $<1.0$ are not considered significant and are shown as a gray dot. Boxes represent areas of regional analysis: $\mathrm{NW}=$ Northwest; $\mathrm{SW}=$ Southwest; $\mathrm{CP}=$ central plains; GL = Great Lakes; $\mathrm{NE}=$ Northeast; and SE $=$ Southeast. These regions are selected to approximate those in Pryor and Schoof (2008) and modified to capture particular geographic features of interest. Results are for the (a) 2-7, (b) 7-20, (c) 20-40, and (d) $>40 \mathrm{yr}^{-1}$ frequency bins. (e) As in (a)-(d), but for values derived from the variance associated with the secular trends found in the observed and stochastically generated records. (f) Median of the normalized PPV within a given frequency bin across the stations within the given region. Values less than 1 indicate that less than half the stations in the region have significant potentially predictable variance within the given bin. Regions are color coded by the color bar on the top of the panel.

time scales (Fig. 1). Median PP is smallest at interannual time scales (defined here as 2-7-yr time scales; Table 1), although relatively large PPV tends to be found west of the Mississippi River basin (Fig. 1a). In comparison, interannual PPV is relatively low over the Great Lakes, as well as along the Atlantic seaboard. At decadal time scales (defined here as 7-20-yr time scales; Fig. 1b), relatively high PPV tends to be found over the Northwest, interior mountain regions, and central plains while relatively low PPV is found over the southernmost portions of the Southwest and the northern Great Plains. In addition, coherent PP values are now found over much of the eastern half of the United States as well. High PP values in these latter regions, as well as over the Southwest, are also found at interdecadal time scales (defined here as 20-40-yr time scales) and multidecadal time scales (defined here as $>40-y r$ time scales; Figs. 1c,d).
For secular trends (Fig. 1e) PPV of annual precipitation occurrence is highest over parts of the Northwest and central plains, the Great Lakes, and the Northeast, although PPV is also evident across other regions of the United States as well.

Figure 1f presents the median PPV of annual precipitation occurrence within select regions. The selection of the median over the mean for this plot and similar plots herein is to avoid the influence of outliers on the analysis. Generally, PPV is most prominent at decadal to multidecadal time scales (Fig. 1f). At shorter time scales, PPV tends to be higher over the Northwest, Southwest, and central plains, while at longer time scales PPV tends to be higher over the Great Lakes, Northeast, and Southeast. The one exception is the Southwest region, which shows the highest PP values (both locally and regionally) at the 20+-yr time scales. 
TABLE 1. Median value of the normalized PPV within a given frequency bin across all stations within the United States. Values in parentheses indicate the fractional number of stations within a given frequency bin that have significant $(p<0.10)$ PP values. Boldface values indicate that more than $50 \%$ of stations have significant values; a plus (+) superscript indicates more than $66 \%$ of stations have significant values and a minus (-) superscript indicates fewer than $33 \%$ of stations have significant value. To calculate the nonnormalized value, see the appendix and Figs. S1-S3 in the supplemental material for conversion factors appropriate for the given characteristic/frequency bin.

\begin{tabular}{llll}
\hline \hline Time scale & \multicolumn{1}{c}{ OCC } & \multicolumn{1}{c}{ SII } & \multicolumn{1}{c}{ TOT } \\
\hline $2-7 \mathrm{yr}$ & $\mathbf{1 . 0 8}(\mathbf{0 . 5 3})$ & $0.53^{-}(0.29)$ & $\mathbf{1 . 1 6}(\mathbf{0 . 5 7})$ \\
$7-20 \mathrm{yr}$ & $\mathbf{1 . 4 4}^{+}(\mathbf{0 . 7 1})$ & $0.63(0.35)$ & $0.94(0.47)$ \\
$20-40 \mathrm{yr}$ & $\mathbf{1 . 3 6}(\mathbf{0 . 6 2})$ & $0.92(0.46)$ & $0.54^{-}(0.32)$ \\
$>40 \mathrm{yr}$ & $\mathbf{1 . 4 1}(\mathbf{0 . 6 0})$ & $\mathbf{1 . 3 2}(\mathbf{0 . 5 7})$ & $0.65(0.40)$ \\
Trend & $\mathbf{1 . 1 8}(\mathbf{0 . 5 3})$ & $0.83(0.46)$ & $0.47^{-}(0.33)$ \\
\hline
\end{tabular}

We will investigate potential sources of this lowfrequency predictability in the next section.

Next we investigate PP in annual precipitation intensity at different time scales (Fig. 2). As with annual precipitation occurrence, median PP of annual intensity is smallest at interannual time scales (Table 1). Regionally, only portions of the coastal Northwest and along the Mississippi River basin show coherent PP values at these time scales (Fig. 2a). Unlike with annual precipitation occurrence, however, the PP of annual intensity changes remains low at decadal time scales as well, although regionally coherent PPV at these time scales can be found over the Northwest, the Ohio River basin, and the Southeast plains (Fig. 2b). Instead, PPV of annual precipitation intensity tends to be found at 20+-yr time scales (Figs. 2c,d)-particularly at the lowest frequencies (Fig. 2d) - across much of the United States, although relatively low PPV is present over the coastal Southwest and the northern Great Plains. For secular trends (Fig. 2e) PPV is highest over the Northeast, Great Lakes, and central plains regions, with relatively low PPV west of the Great Plains.

Examining the median PPV of annual precipitation intensity within select regions, we find it generally increases at longer periods, with highest PPV found at the 40+-yr time scales (Fig. 2f). Regionally, both the Southwest and Northwest have relatively high PPV at the decadal time scales. At multidecadal time scales, PPV of annual precipitation intensity remains prominent in all regions except the Northwest. At the secular trend time scale the Northeast shows the highest PP values in annual-mean intensity, in agreement with other studies (Balling and Goodrich 2011; Wu 2015; Anderson et al. 2015b).

Finally, we investigate PP in annual precipitation accumulations at different time scales (Fig. 3), a metric that has the lowest overall PP of all annual precipitation characteristics (Gianotti et al. 2014). That said, at interannual time scales annual precipitation accumulation tends to have the highest PPV of the three annual characteristics (Table 1). Interannual PPV is relatively high along the West Coast, as well as over the interior Southwest and the central plains extending along the central Mississippi River basin and into the Southeast (Fig. 3a). By contrast, interannual PPV is particularly low over the Great Lakes and Northeast regions. At decadal time scales (Fig. 3b), PPV remains relatively high along the West Coast, interior Northwest, and much of the central plains and the Northeast. By contrast, decadal-scale PPV is relatively low over the midAtlantic region and the Southeast, as well as over the southernmost portions of the Southwest. PPV of annual precipitation accumulations tends to be lowest at the interdecadal time scales (Fig. 3c), with the exception of some regions that show coherent PP values, such as the Northeast and the Ohio River basin. However, PPV tends to increase at multidecadal time scales (Fig. 3d), particularly over the Southwest and interior Northwest, over the northern central plains, the Ohio River basin, and the Northeast. For secular trends (Fig. 3e) PPV is highest over the Great Lakes and Northeast, although there are additional regions that show coherent PPV such as the high plains.

When aggregating over the six regions (Fig. 3f), interannual PPV tends to be highest over the Northwest, Southwest, and central plains, although interannual PPV also is prominent over the Southeast. By contrast, at interannual time scales there is near-zero PP of annual precipitation variations over the Northeast. At decadal time scales, the most prominent PPV tends to be over the Northwest, while at inter- and multidecadal time scales, PP of annual precipitation accumulations is relatively high over the Northeast and Southwest. By contrast, despite having relatively high multidecadal PPV for annual precipitation occurrence and intensity (Figs. 1f, 2f), at these same time scales the Southeast has near-zero annual precipitation accumulation PPV.

The above analysis-particularly at the regional level-suggests substantial variations in the PP of precipitation as a function of both metric and time scale. To examine the regional sensitivity of potentially predictable precipitation characteristics at various time scales, we create a "spectrum" of PPV for the six selected regions found in Figs. 1-3. To remove artificial peaks (and troughs) of predictability, the PP spectra are averaged across 2-yr wide bins (such that the number of spectra within a given averaging bin varies with frequency) and normalized by the $p<0.10$ value (derived from the stochastically generated distribution of smoothed 


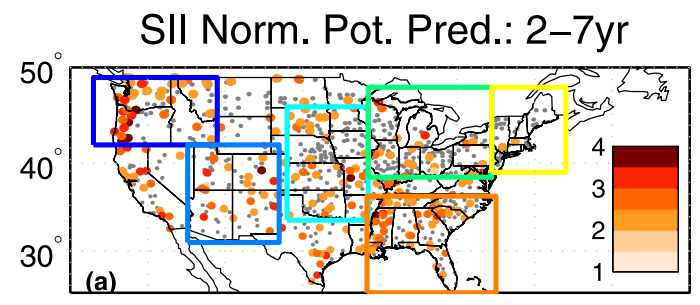

SII Norm. Pot. Pred.: 20-40yr

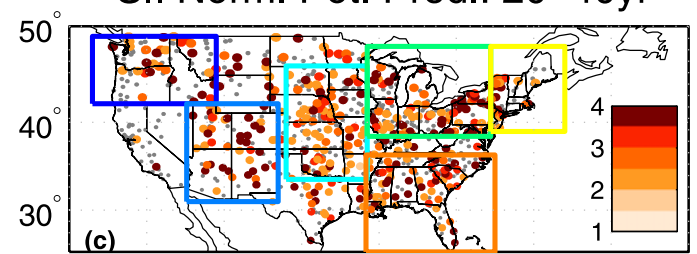

SIl Norm. Pot. Pred.: Trend

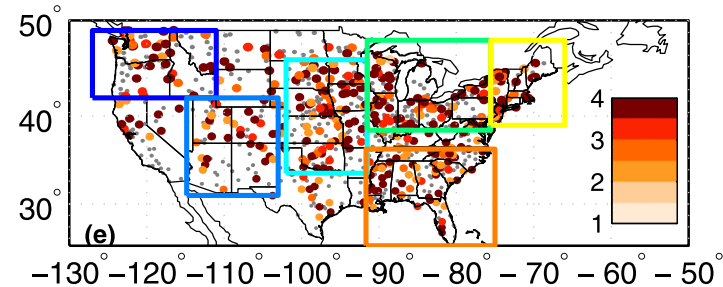

SIl Norm. Pot. Pred.: 7-20yr

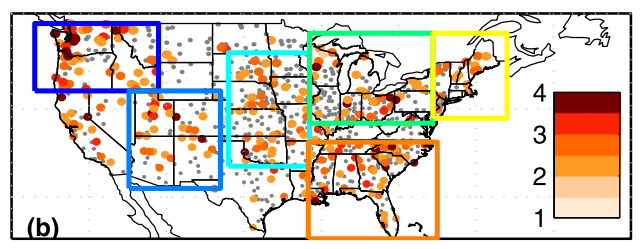

SII Norm. Pot. Pred.: $>40 \mathrm{yr}$

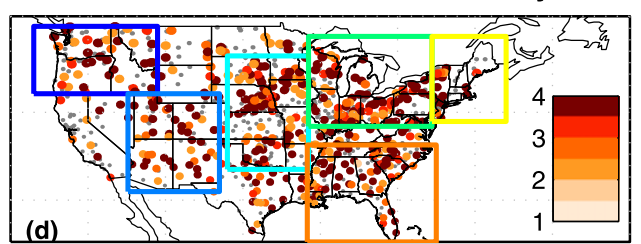

Regional Pot. Pred.: SII

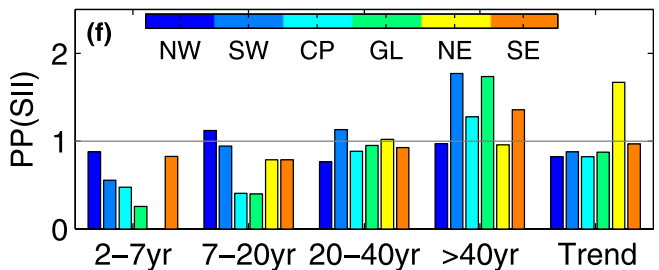

FIG. 2. As in Fig. 1, but for annual precipitation intensity (SII; mm per event).

spectra values for each station within the region). The normalized PP values are then aggregated across a given region by determining the median value.

The PP spectra for the three precipitation metrics as a function of time scale and region are shown in Fig. 4. Over the Northwest (Fig. 4a), there is a strong biennial component to the PPV of both precipitation occurrence and total accumulation, in agreement with past studies (e.g., Johnstone 2011, and references therein). By contrast, very little signal is seen at other interannual time scales, particularly those related to ENSO variability (i.e., 3-6-yr time scales; Diaz and Pulwarty 1994), suggesting that ENSO does not provide substantial predictability to precipitation over the Northwest, at least when annually aggregated. Instead, substantial PPV of precipitation accumulation and occurrence is found at quasi-decadal time scales (here defined as approximately 10-yr time scales). Given the PP values at these time scales, further analysis on sources of this PPV will be analyzed in the next section. At longer time scales $(40+\mathrm{yr})$, there is another local PP maximum for annual precipitation accumulation, which corresponds to a peak in annual precipitation intensity PPV and is likely attributed to the influence of the Pacific decadal oscillation (PDO; Cayan et al. 1998; Nigam et al. 1999; Bitz and Battisti 1999; Steinman et al. 2012).

Over the Southwest (Fig. 4b), there are relatively low PPV values in all three annual precipitation characteristics across interannual time scales, despite the fact that when integrated across these time scales both annual accumulation and occurrence PP values are relatively robust (cf. Figs. 1f, 3f). This discrepancy suggests that at the interannual time scale, there can be year-to-year potentially predictable variations in these two characteristics but with no preferred frequency; that is, the PPV spectrum within this frequency bin is relatively flat (e.g., Anderson et al. 2010). At decadal scales, PPV of precipitation occurrence, and less so of total accumulation, becomes more robust. However the most robust PP values for all three precipitation metrics are at the 20+-yr time scales. Again, given the strength of the PP values at these time scales, further analysis of sources of this PPV-particularly that of annual precipitation occurrence-will be analyzed in the next section.

Over the central plains region (Fig. 4c), interannual PPV tends to be dominated by high-frequency (2-3 yr) variations. In addition, there is a quasi-decadal signature to annual occurrence PPV, although it is not as robust as that found in the Northwest. At longer time scales $(40+\mathrm{yr})$, there is a steady rise in the PPV associated with annual precipitation intensity and to a lesser extent annual precipitation occurrence, in agreement with Figs. 1e and 2e. Somewhat similar spectral characteristics are found over the Great Lakes region (Fig. 4d) with relatively high PPV 


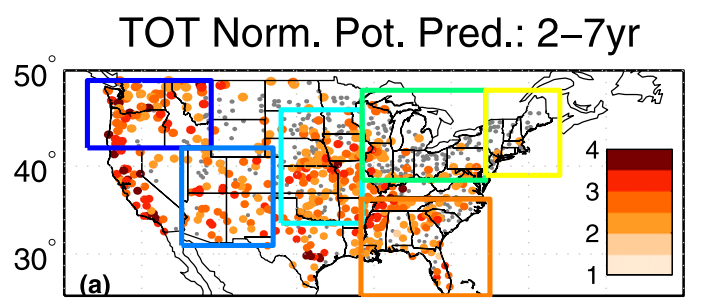

TOT Norm. Pot. Pred.: 20-40yr

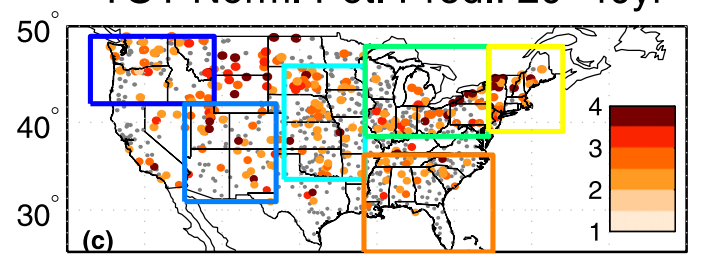

TOT Norm. Pot. Pred.: Trend

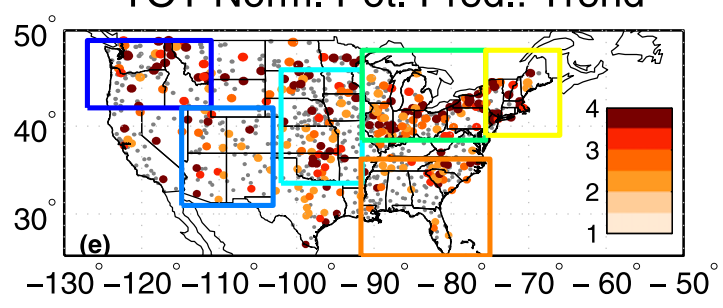

TOT Norm. Pot. Pred.: 7-20yr

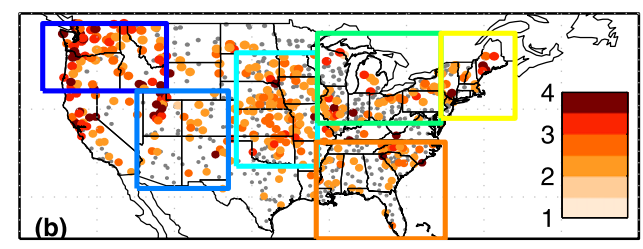

TOT Norm. Pot. Pred.: $>40 \mathrm{yr}$

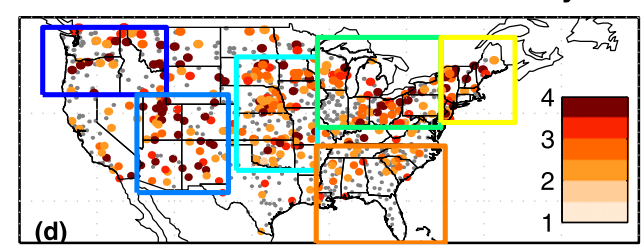

Regional Pot. Pred.: TOT

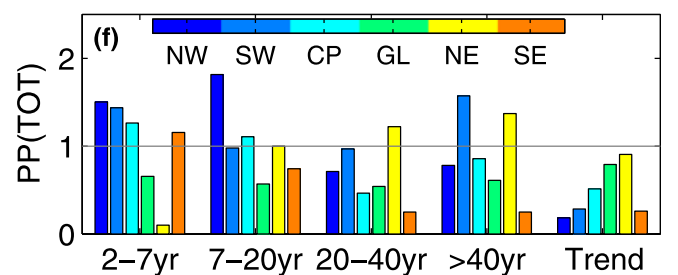

FIG. 3. As in Fig. 1, but for annual precipitation accumulation (TOT; $\mathrm{mm} \mathrm{yr}^{-1}$ ).

in annual precipitation occurrence at approximately 10-yr time scales (albeit with slightly less than half the stations exceeding the $p<0.10$ threshold) and high PPV in annual precipitation occurrence and intensity at multidecadal time scales. However, despite the high PP values of these two characteristics, the PPV of annual total accumulation remains relatively low. A similar phenomenon appears in the Southeast, as discussed below. At interannual time scales, PPV over the Great Lakes is very low for all three metrics, in agreement with Figs. 1f, 2f, and 3f.

The lack of PP variance at the interannual time scales for all metrics is mirrored over the Northeast (Fig. 4e). Instead, predominant sources of PPV for annual precipitation occurrence and total accumulation in this region are found at the decadal to multidecadal time scales, with all three precipitation characteristics showing a general rise in PPV such that at the longest time scales $(60+\mathrm{yr}$, as well as those of the secular trend; cf. Figs. 1f, $2 \mathrm{f}$, and $3 \mathrm{f}), \mathrm{PPV}$ in this region tends to be larger than in any of the other regions analyzed (with the possible exception of the Southwest). These results suggest a longterm transition in the occurrence, intensity, and overall total precipitation across the Northeast (e.g., Pryor et al. 2009; Booth et al. 2012; De Martino et al. 2013; Wu 2015; Anderson et al. 2015b).

Finally, turning to the Southeast, we find relatively high PP values in annual total accumulation at the 4-6-yr time scale, suggestive of an ENSO-related influence on total precipitation in this region (Ropelewski and Halpert 1986; Eichler and Higgins 2006; Ferreira et al. 2013). At longer time scales, however, PPV of annual precipitation intensity and total accumulation are relatively low, although there remains a quasi-decadal peak in PPV of annual precipitation occurrence in agreement with earlier results (cf. Fig. 1f). More interestingly, at multidecadal time scales $(40+y r)$ there is a robust increase in the PPV of both annual precipitation intensity and occurrence. However, multidecadal PPV of annual total accumulation is near zero, suggesting that the potentially predictable changes in precipitation intensity are offset by potentially predictable changes in precipitation occurrence (i.e., at these longer time scales the potentially predictable changes in the two characteristics are of opposite sign).

\section{b. Sources of decadal to multidecadal potentially predictable variability}

In the previous section we performed a spatial and temporal disaggregation of various potentially predictable annual precipitation characteristics. To highlight the utility of this disaggregation, in this section we select for further analysis two robust signals that stood out for us, namely 1) the 20-60-yr time scale PPV of annual precipitation occurrence over the Southwest and 2) the 

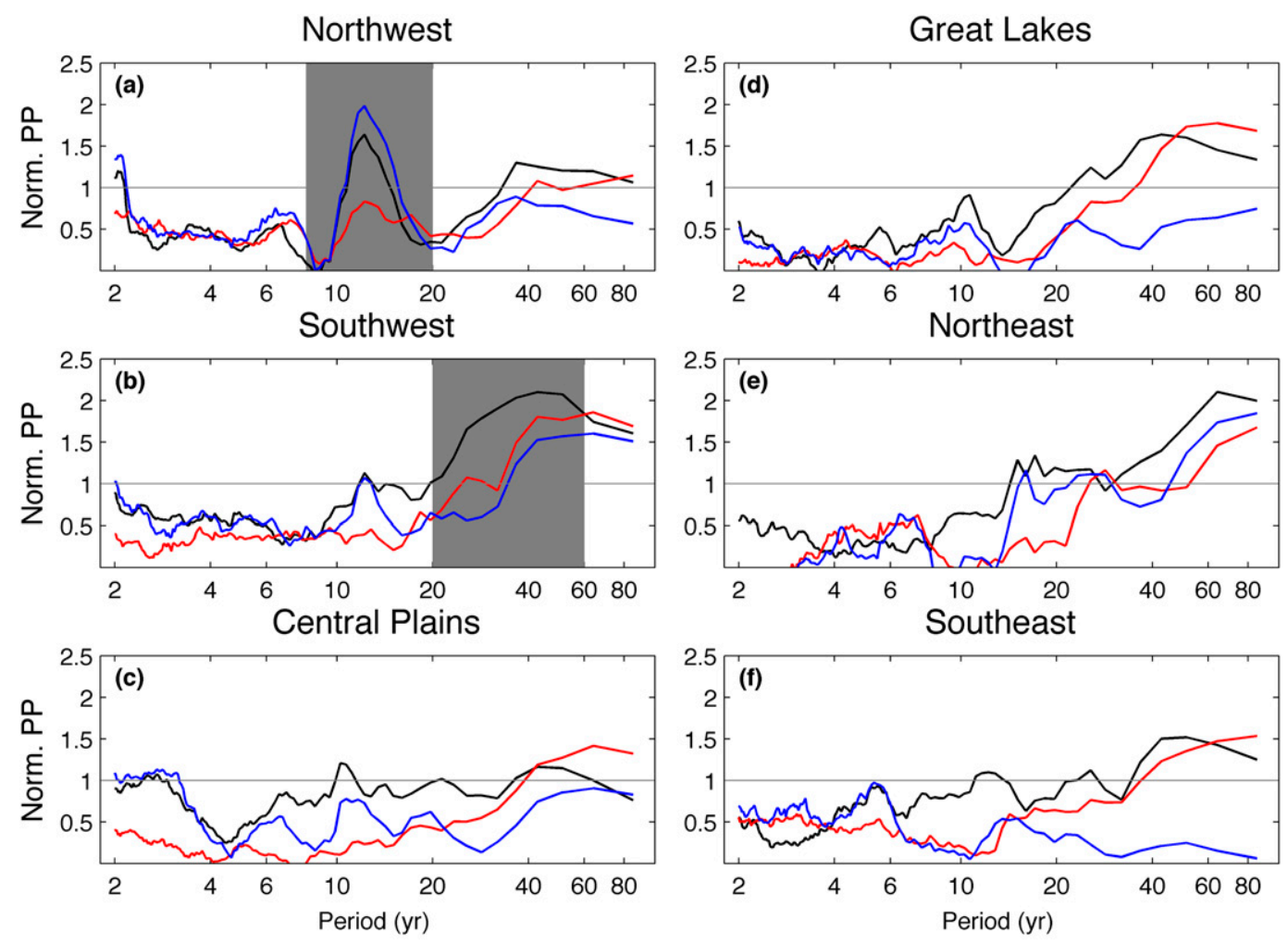

OCC

SII

TOT

FIG. 4. Median normalized PPV of annual precipitation characteristic across stations within given regions, plotted as a function of time scale (period). Regions designated by boxes in Figs. 1-3. For each frequency bin, the normalized PPV at each station is calculated as in Eq. (5) and normalized by the 90th percentile threshold $(p<0.10)$ value derived from stochastically generated records for that station. The median PPV is then calculated for all stations within a region. Annual precipitation characteristics color coded by the color bar on the bottom of the figure: OCC (black), SII (red), and TOT (blue). Regions include the (a) Northwest, (b) Southwest, (c) central plains, (d) Great Lakes, (e) Northeast, and (f) Southeast. Gray shaded regions represent time scales for further analysis within the given region.

approximately 10-yr time scale PPV of annual precipitation accumulation (and occurrence) over the Northwest. Below we analyze in more detail sources of the PPV at these time scales and for these regions, recognizing that there are other potentially predictable annual precipitation characteristics that will have to remain unanalyzed until later.

\section{1) INTER- TO MULTIDECADAL VARIABILITY IN SOUTHWEST PRECIPITATION}

Here we start with an analysis for the PPV of annual precipitation occurrence over the Southwest. To start, we perform a $20-60$-yr bandpass filter on the annual precipitation occurrence time series at each station in the Southwest. Then, a principal component analysis (PCA) is performed on the time series to identify the leading mode of covariability among the stations within this region. The leading principal component (PC) time series, normalized by its year-to-year standard deviation, is presented in Fig. 5a. The time series suggests relatively frequent occurrence of precipitation throughout the 1930s and 1980s, with relatively low occurrence during the early 1950s and at the beginning of the twenty-first century, all of which corresponds to known decadal fluctuations in overall precipitation in this region (Dai 2013). To characterize the spatial structure of this leading mode of low-frequency variability we regress the normalized principal component time series against the observed annual precipitation occurrence time series for all 774 stations across the United States (Fig. 5b). Results suggest that the leading mode of low-frequency variability in annual precipitation occurrence encompasses the entire Southwest (which need not be the case and can only be determined a posteriori via PCA). In addition, this mode of low-frequency variability is accompanied by annual precipitation occurrence variations of similar sign across much of the southern Great Plains and interior plains west of the Mississippi; it is also accompanied by 
Southwest 20-60yr OCC: PC(1) Time-series

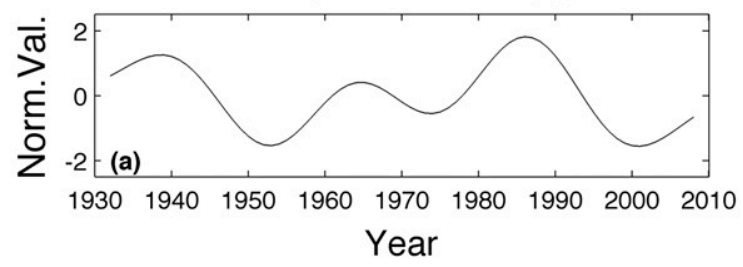

Regress. of OCC(ann) w/PC(1)
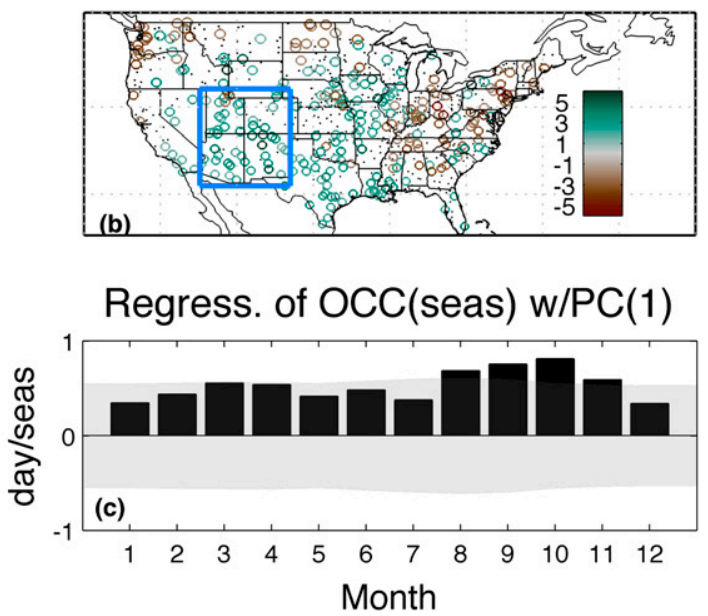

FIG. 5. (a) Standardized first PC time series of 20-60-yr bandpassfiltered OCC for all stations found in the Southwest, as delineated by the box in (b). (b) Regression (circles; days $\mathrm{yr}^{-1}$ ) of the first PC time series against the OCC for all stations across the continental United

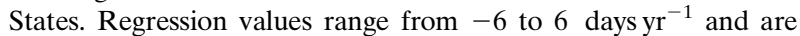
designated by the color bar on the rhs. Stations that fail to meet the $p<0.10$ threshold derived from stochastically generated records for that station are shown as gray dots. (c) Regression of the first PC time series against the seasonal precipitation occurrence for all stations found in the Southwest. Seasonal precipitation time series are based on year-to-year variations in precipitation occurrences within the 91-day window centered on the given month. Bars provide the median regression value for all stations within the Southwest, as delineated by the box in (b). Gray shading indicates the $p>0.10$ threshold, based upon the median of the $p=0.10$ regression values derived from stochastically generated records from each station within the Southwest.

annual precipitation occurrence variations of opposite sign over the Ohio River basin and the Northeast, suggesting potentially predictable, continental-scale changes in annual precipitation occurrence (and total accumulation; Dai 2013) associated with this mode of variability.

In addition to isolating the spatial and temporal characteristics of this low-frequency mode of variability, we are also interested in isolating its seasonal characteristics. Toward this end, for each station in the Southwest, we calculate the year-to-year variations in seasonal precipitation occurrence, defined as the number of precipitation events within a 91-day window centered on the 15 th of each month. We then regress the resulting time series against the normalized principal component time series. For each 91-day season we then calculate the median regression value for all stations within the Southwest (Fig. 5c) and compare it with the median $p<0.10$ regression value. In general, this mode of low-frequency variability is related to increased seasonal precipitation occurrences throughout the year; however, the most substantial (and significant) increases tend to be found from August into October at the tail end of the monsoon season (Carleton et al. 1990; Stensrud et al. 1995), suggesting that this mode of lowfrequency variability preferentially influences the duration of the monsoon season and its extension into fall.

To discern possible sources of PPV in multidecadal precipitation characteristics over the Southwest, we regress the normalized principal component time series against year-to-year variations in surface temperature and $850-\mathrm{hPa}$ geopotential height fields from 20CRv2 (Fig. 6). Both the surface temperature and height fields are characteristic of patterns associated with the second leading mode of Pacific sea surface temperature (SST) variability (Hartmann 2015)—albeit without tropical signatures in the ocean or atmosphere-and multidecadal variations in precipitation over the Southwest (Dettinger et al. 1998; Dai 2013; Stevenson et al. 2015). Within the ocean, the largest signature is a well-defined, zonally extensive cooling extending from the Kuroshio region across the extratropical Pacific; overlaying this cool-water region are relatively low geopotential height fields that terminate off the west coast of North America. Circulation features that accompany these height anomalies include anomalous southwesterly flow over the central and eastern subtropical North Pacific (not shown) that induces local warming in this region (Vimont et al. 2001, 2003). In addition, it induces anomalous onshore flow of subtropical air masses that could potentially supply the moisture and/or instability for triggering enhanced precipitation events over the Southwest. The exact nature of this triggering on these very long time scales requires further investigation. However, the robust relation of precipitation occurrence (and total accumulation) across the Southwest to long-lived Pacific Ocean states suggests that enhanced monitoring and prediction of these states can help realize the PP of precipitation in these regions, recognizing that the ocean state itself may be a response to changing atmospheric circulations and that the source of PP may arise through, for example, land-atmosphere coupling (Stevenson et al. 2015).

\section{2) DeCAdal VARIABILITY IN NORTHWEST PRECIPITATION}

Next we turn to an analysis for the PPV of annual precipitation accumulations over the Northwest. As 


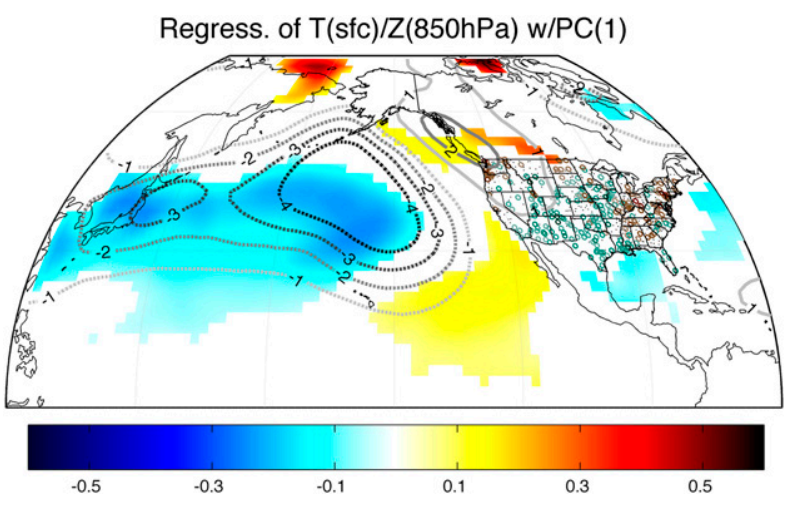

FIG. 6. Regression (shading) of annual near-surface temperatures against the first PC time series of bandpass-filtered OCC over the Southwest (shown in Fig. 5a). Values range from $-0.6^{\circ}$ to $0.6^{\circ} \mathrm{C}$ and are designated by the color bar on the bottom of the panel. Values with $r<0.2$ are masked. Overlaid is regression (contours) of annual $850-\mathrm{hPa}$ heights against the first PC time series of bandpass-filtered OCC over the Southwest. Values contoured every $1 \mathrm{~m}$; minimum contour is $\pm 1 \mathrm{~m}$. Positive (negative) values are shown by solid (dashed) lines. Also overlaid is regression (circles; days $\mathrm{yr}^{-1}$ ) of the first PC time series against the OCC for all stations across the continental United States. Regression values range from -6 to 6 days $\mathrm{yr}^{-1}$.

before a bandpass filter, now corresponding to 7-20-yr periods, is applied to the annual precipitation accumulation time series at each station. A PCA is then performed on stations in the Northwest to identify the leading mode of covariability among the stations within this region (Fig. 7a). The resulting time series suggests a modulation of decadal-scale precipitation in this region, with relatively strong decadal variability starting in the 1970s, relatively weak variability from 1950 to 1970, and more moderate variability prior to that.

The corresponding spatial structure of annual precipitation accumulation (Fig. 7b) indicates that this leading mode of low-frequency variability influences the entire Northwest, with largest anomalies found along the coastal regions extending southward into Northern California. In addition, this mode of low-frequency variability is accompanied by annual precipitation accumulation variations of similar sign across the Intermountain West and the central plains. This geographic structure suggests that the quasi-decadal variability isolated here has a similar origin as that which produces quasi-decadal variability in the interior west (Wang et al. 2010) and interior plains (White et al. 2008; Wang et al. 2014). Indeed, the time series of variability, and its modulation, matches well with quasi-decadal variability in each region [cf. Fig. 4 from Wang et al. (2010) and Fig. 2 from Wang et al. (2014)]. Over the Northwest, this quasi-decadal variability is manifested primarily during the extended winter season (Fig. 7c).
Northwest 7-20yr TOT: PC(1) Time-series

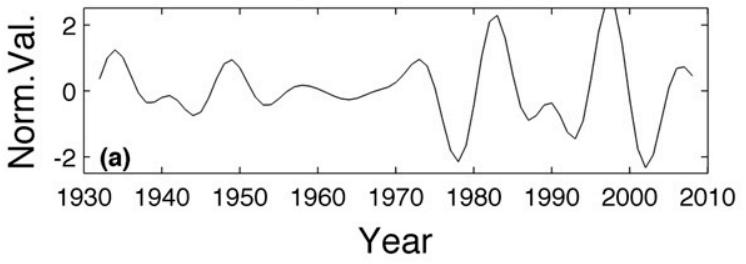

Regress. of TOT(ann) w/PC(1)

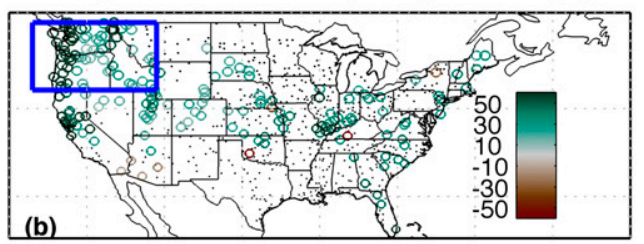

Regress. of TOT(seas) w/PC(1)

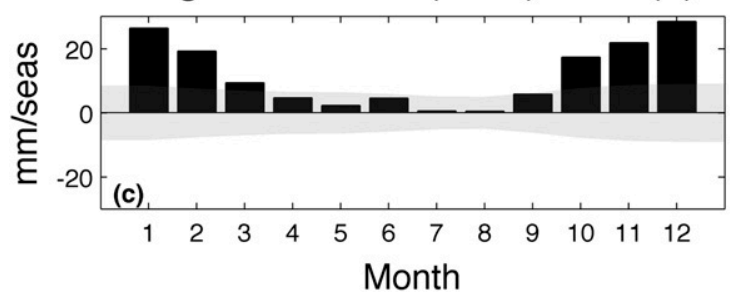

FIG. 7. As in Fig. 5, but for the first PC time series of 7-20-yr bandpass-filtered TOT $(\mathrm{mm})$ for all stations found in the Northwest, as delineated by the box in (b).

To analyze the source of this predictability we perform a similar analysis as we did for the Southwest, but now incorporating lead-lag regression fields to determine the evolution of the ocean and atmosphere states that relate to this mode of quasi-decadal variability (Fig. 8). During anomalously wet (year 0) and dry (years -6 and +5 ) periods over the Northwest, a dipole in $850-\mathrm{hPa}$ geopotential heights is found over the extratropical North Pacific that induces anomalous onshore (year 0) and offshore (years -6 and 5) flow into the Northwest region (Dettinger et al. 1998; Wang et al. 2010; Johnstone 2011). The zonal dipole resembles somewhat the nodes of the east Pacific-North Pacific teleconnection pattern (e.g., Barnston and Livezey 1987; Bell and Janowiak 1995), which is known for strong relationships with precipitation, particularly in the central United States (Bell and Janowiak 1995). Indeed, the easternmost lobe of the dipole pattern extends across the continental United States and contributes to the precipitation variations over the central plains by inducing anomalous southerly (year 0 ) and northerly (years -6 and 5) flow across the interior plains.

Turning to the evolution of the pattern, it appears that the dipole pattern undergoes a systematic shift from more zonal (e.g., year $-6 /-5$ ) to more meridional 

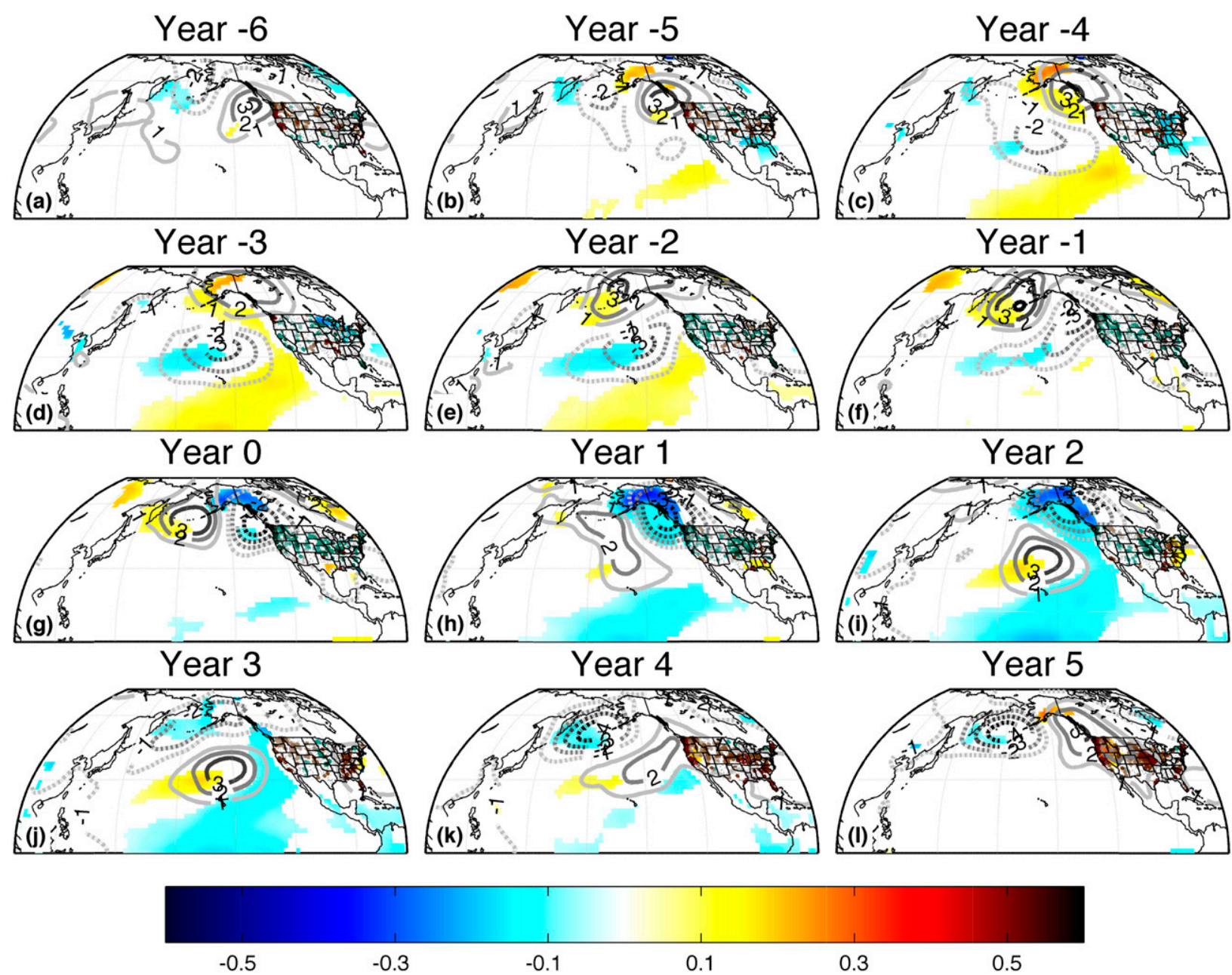

FIG. 8. Lead and lag regression (shading) of annual near-surface temperatures against the first PC time series of bandpass-filtered TOT over the Northwest (shown in Fig. 7a). Values range from $-0.6^{\circ}$ to $0.6^{\circ} \mathrm{C}$ and are designated by the color bar on the bottom of the panel. Values with $r<0.2$ are masked. Overlaid is lead and lag regression (contours) of annual 850-hPa heights against the first PC time series of bandpass-filtered TOT over the Northwest. Values contoured every $1 \mathrm{~m}$; minimum contour is $\pm 1 \mathrm{~m}$. Positive (negative) values are shown by solid (dashed) lines. Also overlaid is lead and lag regression (circles) of TOT for all stations across the continental United States against the first PC time series of bandpass-filtered TOT over the northwestern United States. (a)-(1) Regression fields leading (year $<0$ ), concurrent with (year $=0$ ), and lagging (year $>0$ ) the first PC time series.

(e.g., year $-3 /-2)$ and back (e.g., year $-1 / 0)$. Indeed, the pattern has a distinct counterclockwise evolution to it, which has subsequently been revealed through an analysis of the lower-tropospheric (i.e., $850 \mathrm{hPa}$ ) height fields over the North Pacific (Anderson et al. 2016). Accompanying this evolution are distinct temperature signatures in the North Pacific, including substantial land-based cooling and warming as the dipole shifts from a more zonal to more meridional orientation (i.e., years $0-2$ and year $-5 /-4$ ), which likely give rise to the known quasi-decadal signature along the Gulf of Alaska (Wiles et al. 1998, 2014). In addition, there is extensive ocean-based cooling and warming along the eastern North Pacific, which is most prominent during the meridional orientation of the dipole and is likely a response to dynamic and thermodynamic processes induced by atmospheric circulations associated with this orientation of the dipole pattern (Bond et al. 2015).

By contrast, during peak years of high (year $-1 / 0$ ) or low (year -6 and year 4/5) anomalous precipitation accumulation over the Northwest there is substantially reduced oceanic signal in the North Pacific and no significant oceanic signature in the tropical Pacific, despite the apparent correspondence between two major peaks in the PC time series with the 1982/83 and 1997/98 El Niño events [this result is confirmed by the weak and insignificant correlations of the full PC time series 
against both the year-to-year variations in the Niño-3.4 index as well as the Niño-3.4 index with the same 7-20-yr bandpass filter applied ( $r=-0.04$ and $r=-0.13$, respectively)]. We note that others have argued for an influence of far western tropical Pacific (i.e., Philippine Sea) SSTs on precipitation accumulations in the western United States during these years (e.g., Wang et al. 2011), but we find no evidence for such an influence from this region [in agreement with Dettinger et al. (1998), Johnstone (2011), and Seager et al. (2015); see also results from Wang et al. (2010), cf. their Fig. 6d)]. However, a tropical signature is much more prominent during the intervening years when large-scale ocean temperature anomalies develop over the central equatorial Pacific in conjunction with the meridional orientation of the atmospheric dipole. Indeed, the meridional orientation of the dipole corresponds to the North Pacific Oscillation (NPO), which is driven in part by the central Pacific SST structure during these years (Furtado et al. 2012). It is most likely the tropical influence during these intervening periods that gives rise to the known relation between western United States and central plains precipitation and the tendency in central equatorial Pacific SSTs (Wang et al. 2010, 2014), which maximizes when the anomalous state of the central equatorial Pacific itself is near zero.

In summary, as noted in Anderson et al. (2016) the evolution of the atmospheric height anomaliestermed the Pacific decadal precession (PDP)appears to be driven by the formation of low-frequency anomalies in the central equatorial Pacific, which induces the southward migration of the western lobe of the atmospheric dipole and the establishment of the meridional NPO structure. What is less clear, however, is the mechanism that maintains the dipole structure as the equatorial Pacific anomalies dissipate and the dipole assumes a more zonal orientation. Indeed, this dipole structure is as robust-and contributes more to annual precipitation accumulation anomalies in the Northwest and the central plainsduring these years as it is when the central equatorial Pacific anomalies are fully developed. While an investigation of this mechanism is ongoing, we simply note that the robust relation of precipitation accumulations across the northwestern United States to precursor Pacific Ocean states suggests that enhanced monitoring and prediction of these states can help realize the $\mathrm{PP}$ of precipitation in these regions. In particular, the recognition that precipitation accumulations in the Northwest region tend to maximize 2-3 years after the dissipation of the central equatorial Pacific temperature anomalies may provide long-lead guidance on multiyear water availability in these regions.

\section{Summary}

In the previous section we isolated the dominant time scales at which potentially predictable changes in observed precipitation characteristics occur over the continental United States and then analyzed sources of revealed potentially predictable precipitation variations for particular regions and time scales of interest. Given the broad scope of the analyses, we use this section to both synthesize these results and contextualize them within the climatology of the various regions (Fig. 9). Overall, we find the following:

- At all time scales except interannual, the PPV of annual event occurrence is greater than the PPV of either annual event intensity or annual accumulation. PPV of annual accumulation tends to be relatively strong (weak) at interannual (decadal to multidecadal) time scales, with respect to other time scales and to the other two characteristics. By contrast, the PPV of annual event intensity is relatively weak at interannual time scales but enhanced at multidecadal and secular trend time scales.

- Geographically, PPV of annual event occurrence at different time scales shows divergent behavior as a function of a given station's climatology (Fig. 9a), with multidecadal PPV highest over wet regions and lowest over dry regions. These high PPV values tend to be found across much of the eastern United States (Fig. 1) and the Southwest. By contrast, interannual PPV tends to be highest over dry regions and lowest over wet regions except for the Northwest, where a prominent quasi-biennial peak is present (Fig. 4a).

- In contrast to annual event occurrence, PPV of annual event intensity at different time scales is relatively insensitive to a given station's climatology (Fig. 9b). However, there are still coherent geographical structures to PPV, the most prominent of which includes a notable absence of interannual to decadal PPV across much of the plains, the Great Lakes, and the Northeast (Fig. 2), in contrast to the relatively high multidecadal PPV in those regions as well as the Southwest.

- Also, the PPV of annual accumulation at different time scales shows a more nuanced relation with a given station's climatology (Fig. 9c). In particular, interannual PPV tends to be higher both in relatively dry (Southwest and central plains) and wet (Northwest and Southeast) locations (Fig. 3). Interannual PPV tends to be lower in more temperate climates (e.g., the Northeast). By contrast, secular trends in PPV are largest in these same regions. At multidecadal (and 


\section{$\mathrm{PP}(\mathrm{OCC})$ v. Climatology}
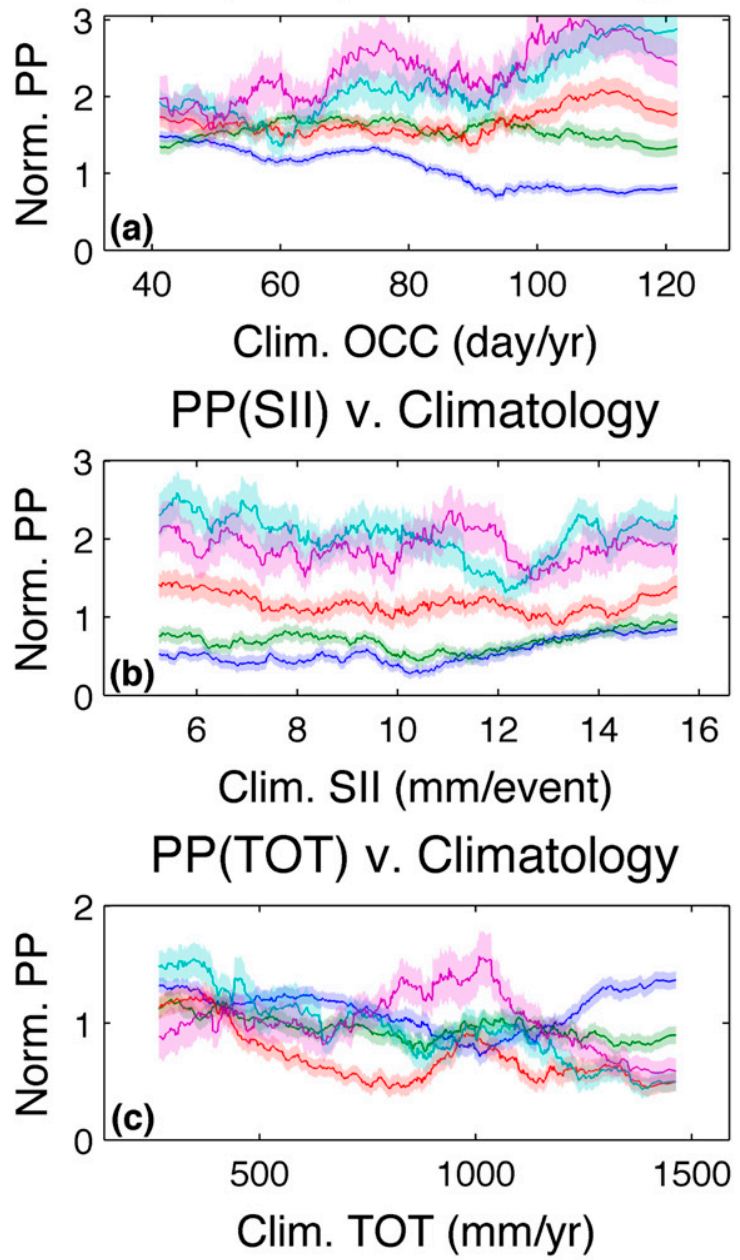

\section{2-7yr 7-20yr 20-40yr $>40 \mathrm{yr} \quad$ Trend}

FIG. 9. (a) Mean normalized potentially predictable fraction of OCC [i.e., $\mathrm{PP}(\mathrm{OCC})$ ] within a given frequency bin plotted as a function of the climatological value of OCC [i.e., Clim(OCC)]. Mean PP(OCC) ( $y$ axis) and mean Clim(OCC) ( $x$ axis) calculated as a running, 100-station mean along the sorted distribution of Clim(OCC) values at all 774 stations across the United States. Shading indicates the standard error on the estimated mean PP (OCC). Frequency bins color coded by the color bar at the bottom of the figure. (b) As in (a), but for SII. (c) As in (a), but for TOT.

secular trend) time scales, PPV of annual accumulation tends to decrease over wet regions, despite relatively robust PPV of the individual precipitation characteristics at these same time scales, suggesting that at these longer time scales the potentially predictable changes in event occurrence and event intensity tend to be of opposite sign.

- Further spectral disaggregation of overall PPV in various locations suggests a robust signal in the interand multidecadal (20-60 yr) time scale PPV of annual precipitation occurrence over the Southwest, which also appears to influence much of the southern Great Plains and is most prominent at the terminus of the monsoon season. Historical variations in precipitation occurrence at these time scales are related to slowly evolving base-state changes in the extratropical North Pacific and accompanying large-scale atmospheric circulations that are conducive to inducing onshore flow of subtropical air masses into the Southwest.

- Similarly there is a robust signal in the quasi-decadal PPV of annual precipitation accumulation over the Northwest, which also appears to influence the Intermountain West and the central plains and is most prominent during extended boreal winter. Historical variations in precipitation occurrence at these time scales are related to a slowly evolving extratropical atmospheric pressure dipole over the North Pacific that rotates counterclockwise. In its meridional orientation it resembles the NPO pattern, which in turn is coincident with warming/cooling over the central tropical Pacific. However, in its zonal orientation - which is the one that induces onshore and offshore flow and is most strongly related to increased and decreased precipitation accumulations in the Northwest and central plains-there is near-zero ocean signal in either the tropical or extratropical ocean basins. As such, it is still unclear what mechanism sustains these circulation features, which appear confined to the extratropics.

\section{Conclusions and discussion}

In this paper, we quantified the dominant time scales of potentially predictable variations in observed precipitation characteristics over the United States. To do so, we first simulated the variance associated with shortmemory meteorological processes using stationary stochastic weather models (SSWMs) constructed from observed station-based daily precipitation records. We then calculated the potentially predictable variance (PPV) as the fraction of the observed variance that can be ascribed to climatic phenomena once the variance arising from the stochastic evolution of typical meteorological events has been subtracted out (Singh and Kripalani 1986). Since these are variance-based quantities, it is possible to estimate the contribution of observed variance at different time scales to the overall PPV through spectral decomposition. The spatio-spectral structure of the PPV can then be used to isolate regions and time scales that may be influenced by climate-induced changes in the underlying precipitation-producing processes.

Overall, these observationally constrained estimates suggest that the potential for predicting precipitation variations in a given region is strongly dependent on the 
time scale of interest. At the same time, two case studies for particular regions and time scales of interest (namely $20-60-y r$ time scale variations of annual precipitation occurrence over the Southwest and approximately 10-yr time scale variations of annual precipitation accumulation over the Northwest) highlight the utility of using PPV to isolate regions, time scales, and characteristics for further analysis. As noted in the introduction, it would be highly informative to evaluate these observationally constrained estimates with similar results derived using output from numerical models used to make climate forecasts, such as from short-term seasonal forecasting systems or long-term climate simulation systems. Such analyses in turn could 1) help assess sources of error in these forecasts arising either from a lack of climate-induced precipitation response and/or erroneous stochastic short-memory behavior within the models, 2) help develop observationally constrained skill masks that can be applied to these forecasts, and 3) ultimately help quantify realizable "room for improvement" between potential and actual precipitation predictability (Kumar et al. 2014). Such work is ongoing and will be reported in a subsequent manuscript.

Acknowledgments. This work was supported by the National Science Foundation (AGS-0958907; received by BTA, GDS, and DJSG) and Department of Energy (DE-SC0006914; received by BTA, GDS, and DJSG).

\section{APPENDIX}

\section{Normalization of PPV}

In this paper, we estimated the contribution of observed variance at different time scales to the overall PPV through spectral decomposition. For presentation purposes, in many cases we subsequently normalized these values by the 90th percentile threshold $(p<0.10)$ value derived from the cumulative distribution of potential predictability values, as returned by 1000 stochastically generated $80+-y r$ records for that station. We do so because the unequal size of the frequency bins influences the magnitude of PPV found within the bins. To see this influence, Figs. S1-S3 in the supplemental material show the actual PPV plotted against the normalized PPV for the three precipitation characteristics (annual accumulation, annual event occurrence, and annual event intensity) and four frequency bins $(2-7,7-20,20-40$, and $40+\mathrm{yr}^{-1}$ ). Also shown are the $p<0.10 \mathrm{PP}$ values for all stations for the same precipitation characteristics and the same frequency bins. Most importantly, there is a strong linear relation between the actual PP values and the normalized PP values (blue dots), indicating that the presentation of normalized PP values throughout is not unduly skewing the results. In addition, it can be seen that while the observed PP values tend to decrease with decreasing frequency, as shown by the median value (blue line), this decrease is influenced (in part) by the binning itself, as shown by the accompanying decrease in stochastically generated PP values within each bin, as represented by the red dots and their median (red line). To remove this artifact, we chose to normalize the observed PPV by the $p<0.10 \mathrm{PPV}$, which in turn allows us to visualize where, and at what time scales, observed PPV is highest in terms of its significance. That said, if the reader is interested, it is possible to convert the normalized PPV found in the figures (for a given characteristic or frequency bin) to an approximate nonnormalized PPV either visually using Figs. S1-S3 in the supplemental material or numerically using the linear approximation provided on the graphs.

\section{REFERENCES}

Allen, M. R., and W. J. Ingram, 2002: Constraints on future changes in climate and the hydrologic cycle. Nature, 419, 224-232, doi:10.1038/nature01092.

Anderson, B. T., and Coauthors, 2010: Observed trends in summertime precipitation over the southwestern United States. J. Climate, 23, 1937-1944, doi:10.1175/2009JCLI3317.1.

, D. J. S. Gianotti, and G. D. Salvucci, 2015a: Characterizing the potential predictability of station-based seasonal extremes in precipitation accumulations and dry-spell durations. J. Hydrometeor., 16, 843-856, doi:10.1175/JHM-D-14-0111.1.

,-- , and,$- 2015 \mathrm{~b}$ : Detectability of historical trends in station-based precipitation characteristics over the continental United States. J. Geophys. Res. Atmos., 120, 4842-4859, doi:10.1002/2014JD022960.

,-- J J. Furtado, and E. Di Lorenzo, 2016: A decadal precession of atmospheric pressures over the North Pacific. Geophys. Res. Lett., 43, 3921-3927, doi:10.1002/2016GL068206.

Balling, R. C., Jr., and G. B. Goodrich, 2011: Spatial analysis of variations in precipitation intensity in the USA. Theor. Appl. Climatol., 104, 415-421, doi:10.1007/s00704-010-0353-0.

Barnston, A. G., and R. E. Livezey, 1987: Classification, seasonality and persistence of low-frequency atmospheric circulation patterns. Mon. Wea. Rev., 115, 1083-1126, doi:10.1175/ 1520-0493(1987)115<1083:CSAPOL > 2.0.CO;2.

Becker, E. J., H. van den Dool, and M. Peña, 2013: Short-term climate extremes: Prediction skill and predictability. J. Climate, 26, 512-531, doi:10.1175/JCLI-D-12-00177.1.

Bell, G. D., and J. E. Janowiak, 1995: Atmospheric circulation associated with the Midwest floods of 1993. Bull. Amer. Meteor. Soc., 76, 681-695, doi:10.1175/1520-0477(1995)076<0681: ACAWTM $>2.0 . \mathrm{CO} ; 2$

Bitz, C. C., and D. S. Battisti, 1999: Interannual to decadal variability in climate and the glacier mass balance in Washington, western Canada, and Alaska. J. Climate, 12, 3181-3196, doi:10.1175/1520-0442(1999)012<3181:ITDVIC > 2.0.CO;2.

Boer, G. J., 2000: A study of atmosphere-ocean predictability on long time scales. Climate Dyn., 16, 469-477, doi:10.1007/ s003820050340.

, 2004: Long time-scale potential predictability in an ensemble of coupled climate models. Climate Dyn., 23, 29-44, doi:10.1007/ s00382-004-0419-8. 
—_, and S. J. Lambert, 2008: Multi-model decadal potential predictability of precipitation and temperature. Geophys. Res. Lett., 35, L05706, doi:10.1029/2008GL033234.

Bond, N. A., M. F. Cronin, H. Freeland, and N. Mantua, 2015: Causes and impacts of the 2014 warm anomaly in the NE Pacific. Geophys. Res. Lett., 42, 3414-3420, doi:10.1002/2015GL063306.

Booth, E. L. J., J. M. Byrne, and D. L. Johnson, 2012: Climatic changes in western North America, 1950-2005. Int. J. Climatol., 32, 2283-2300, doi:10.1002/joc.3401.

Carleton, A. M., D. A. Carpenter, and P. J. Weser, 1990: Mechanisms of interannual variability of the southwest United States summer rainfall maximum. J. Climate, 3, 999-1015, doi:10.1175/ 1520-0442(1990)003<0999:MOIVOT>2.0.CO;2.

Cayan, D. R., M. D. Dettinger, H. F. Diaz, and N. E. Graham, 1998: Decadal variability of precipitation over western North America. J. Climate, 11, 3148-3166, doi:10.1175/1520-0442(1998)011<3148: DVOPOW $>2.0 . \mathrm{CO} ; 2$.

Collins, M., 2002: Climate predictability on interannual to decadal time scales: The initial value problem. Climate Dyn., 19, 671692, doi:10.1007/s00382-002-0254-8.

Compo, G. P., and Coauthors, 2011: The Twentieth Century Reanalysis Project. Quart. J. Roy. Meteor. Soc., 137, 1-28, doi:10.1002/qj.776.

Dai, A., 2013: The influence of the inter-decadal Pacific oscillation on US precipitation during 1923-2010. Climate Dyn., 41, 633646, doi:10.1007/s00382-012-1446-5.

De Martino, G., N. Fontana, G. Marini, and V. P. Sing, 2013: Variability and trend in seasonal precipitation in the continental United States. J. Hydrol. Eng., 18, 630-640, doi:10.1061/ (ASCE)HE.1943-5584.0000677.

Dettinger, M. D., D. R. Cayan, H. F. Diaz, and D. M. Meko, 1998: North-south precipitation patterns in western North America on interannual-to-decadal timescales. J. Climate, 11, 3095-3111, doi:10.1175/1520-0442(1998)011<3095:NSPPIW>2.0.CO;2.

Diaz, H. F., and R. S. Pulwarty, 1994: An analysis of the time scales of variability in centuries-long ENSO-sensitive records in the last 1000 years. Climatic Change, 26, 317-342, doi:10.1007/ BF01092422.

Eade, R., and Coauthors, 2014: Do seasonal-to-decadal climate predictions underestimate the predictability of the real world? Geophys. Res. Lett., 41, 5620-5628, doi:10.1002/2014GL061146.

Eichler, T., and W. Higgins, 2006: Climatology and ENSO-related variability of North American extratropical cyclone activity. J. Climate, 19, 2076-2093, doi:10.1175/JCLI3725.1.

Ferreira, R. N., L. Hall, and T. M. Rickebach, 2013: A climatology of the structure, evolution, and propagation of midlatitude cyclones in the southeast United States. J. Climate, 26, 84068421, doi:10.1175/JCLI-D-12-00657.1.

Furtado, J. C., E. Di Lorenzo, B. T. Anderson, and N. Schneider, 2012: Linkages between the North Pacific Oscillation and central tropical Pacific SSTs at low frequencies. Climate Dyn., 39, 2833-2846, doi:10.1007/s00382-011-1245-4.

Gianotti, D. J., B. T. Anderson, and G. D. Salvucci, 2013: What do rain gauges tell us about the limits of precipitation predictability? J. Climate, 26, 5682-5688, doi:10.1175/ JCLI-D-12-00718.1.

,$- \ldots$, and — 2014: The potential predictability of precipitation occurrence, intensity, and seasonal totals over the continental United States. J. Climate, 27, 6904-6918, doi:10.1175/JCLI-D-13-00695.1.

Goddard, L., and Coauthors, 2013: A verification framework for interannual-to-decadal predictions experiments. Climate Dyn., 40, 245-272, doi:10.1007/s00382-012-1481-2.
Gregory, J. M., T. M. L. Wigley, and P. D. Jones, 1993: Application of Markov models to area-average daily precipitation series and interannual variability in seasonal totals. Climate Dyn., $\mathbf{8}$, 299-310, doi:10.1007/BF00209669.

Groisman, P. Ya., and R. W. Knight, 2008: Prolonged dry episodes over the conterminous United States: New tendencies emerging during the last 40 years. J. Climate, 21, 1850-1862, doi:10.1175/2007JCLI2013.1.

Hartmann, D. L., 2015: Pacific sea surface temperature and the winter of 2014. Geophys. Res. Lett., 42, 1894-1902, doi:10.1002/ 2015 GL063083.

Hoskins, B. J., 2013: The potential for skill across the range of the seamless weather-climate prediction problem: A stimulus for our science. Quart. J. Roy. Meteor. Soc., 139, 573-584, doi:10.1002/ qj.1991.

Hurvich, C. M., and C.-L. Tsai, 1989: Regression and time series model selection in small samples. Biometrika, 76, 297-307, doi:10.1093/biomet/76.2.297.

Jia, L., and T. DelSole, 2012: Multi-year predictability of temperature and precipitation in multiple climate models. Geophys. Res. Lett., 39, L17705, doi:10.1029/2012GL052778.

Johnstone, J. A., 2011: A quasi-biennial signal in western US hydroclimate and its global teleconnections. Climate Dyn., $\mathbf{3 6}$, 663-680, doi:10.1007/s00382-010-0755-9.

Katz, R. W., 1977: Precipitation as a chain-dependent process. J. Appl. Meteor., 16, 671-676, doi:10.1175/1520-0450(1977)016<0671: PAACDP $>2.0 . C O ; 2$.

— stochastic modeling of precipitation. J. Climate, 11, 591-601, doi:10.1175/1520-0442(1998)011<0591:OPISMO > 2.0.CO;2.

Koster, R. D., and Coauthors, 2004: Regions of strong coupling between soil moisture and precipitation. Science, 305, 11381140, doi:10.1126/science.1100217.

Kumar, A., P. Pen, and M. Chen, 2014: Is there a relationship between potential and actual skill? Mon. Wea. Rev., 142, 22202227, doi:10.1175/MWR-D-13-00287.1.

Leith, C., 1978: Predictability of climate. Nature, 276 (Suppl.), 352355, doi:10.1038/276352a0.

Madden, R. A., 1976: Estimates of the natural variability of timeaveraged sea-level pressure. Mon. Wea. Rev., 104, 942-952, doi:10.1175/1520-0493(1976)104<0942:EOTNVO>2.0.CO;2. - and D. J. Shea, 1978: Estimates of the natural variability of time-averaged temperatures over the United States. Mon. Wea. Rev., 106, 1695-1703, doi:10.1175/1520-0493(1978)106<1695: EOTNVO $>2.0 . \mathrm{CO} ; 2$.

Moron, V., A. W. Robertson, and M. N. Ward, 2006: Seasonal predictability and spatial coherence of rainfall characteristics in the tropical setting of Senegal. Mon. Wea. Rev., 134, 32483262, doi:10.1175/MWR3252.1.

Nigam, S., M. Barlow, and E. H. Berbery, 1999: Analysis links Pacific decadal variability to drought and streamflow in the United States. Eos, Trans. Amer. Geophys. Union, 80, 621625, doi:10.1029/99EO00412.

Pal, I., B. T. Anderson, G. D. Salvucci, and D. Gianotti, 2013: Magnitude and significance of observed trends in precipitation frequency over the U.S. 25th Conf. on Climate Variability and Change, Austin, TX, Amer. Meteor. Soc., 13B.3. [Available online at https://ams.confex.com/ams/93Annual/webprogram/ Paper215439.html.]

Peterson, T. C., and Coauthors, 2001: Report on the activities of the Working Group on Climate Change Detection and related rapporteurs 1998-2001. WMO Rep. WCDMP-47, WMO-TD 1071, 143 pp. [Available online at http://www.clivar.org/node/289.] 
Pryor, S. C., and J. T. Schoof, 2008: Changes in the seasonality of precipitation over the contiguous USA. J. Geophys. Res., 113, D21108, doi:10.1029/2008JD010251.

_ J. A. Howe, and K. E. Kunkel, 2009: How spatially coherent and statistically robust are temporal changes in extreme precipitation in the contiguous USA? Int. J. Climatol., 29, 31-45, doi:10.1002/joc.1696.

Reek, T., S. R. Doty, and T. W. Owen, 1992: A deterministic approach to the validation of historical daily temperature and precipitation data from the cooperative network. Bull. Amer. Meteor. Soc., 73, 753-762, doi:10.1175/1520-0477(1992)073<0753: ADATTV $>2.0 . \mathrm{CO} ; 2$.

Ropelewski, C. F., and M. S. Halpert, 1986: North American precipitation and temperature patterns associated with the El Niño/Southern Oscillation (ENSO). Mon. Wea. Rev., 114, 2352-2362, doi:10.1175/1520-0493(1986)114<2352: NAPATP $>2.0 . \mathrm{CO} ; 2$.

Rowell, D. P., 1998: Assessing potential seasonal predictability with an ensemble of multidecadal GCM simulations. J. Climate, 11, 109-120, doi:10.1175/1520-0442(1998)011<0109: APSPWA $>2.0 . \mathrm{CO} ; 2$.

Schubert, S. D., and Coauthors, 2008: Potential predictability of long-term drought and pluvial conditions in the US Great Plains. J. Climate, 21, 802-816, doi:10.1175/2007JCLI1741.1.

Seager, R., M. Hoerling, S. Schubert, H. Wang, B. Lyon, A. Kumar, J. Nakamura, and N. Henderson, 2015: Causes of the 2011-14 California drought. J. Climate, 28, 6997-7024, doi:10.1175/ JCLI-D-14-00860.1.

Shea, D. J., and R. A. Madden, 1990: Potential for long-range prediction of monthly mean surface temperatures over North America J. Climate, 3, 1444-1451, doi:10.1175/1520-0442(1990)003<1444: PFLRPO $>2.0 . \mathrm{CO} ; 2$.

Singh, S. W., and R. H. Kripalani, 1986: Potential predictability of lower-tropospheric monsoon circulation and rainfall over India. Mon. Wea. Rev., 114, 758-763, doi:10.1175/ 1520-0493(1986)114<0758:PPOLTM >2.0.CO;2.

Smith, D. M., A. A. Scaife, and B. P. Kirtman, 2012: What is the current state of scientific knowledge with regard to seasonal and decadal forecasting? Environ. Res. Lett., 7, 015602, doi:10.1088/1748-9326/7/1/015602.

Steinman, B. A., M. B. Abbott, M. E. Mann, N. D. Stansell, and B. P. Finney, 2012: 1,500 year quantitative reconstruction of winter precipitation in the Pacific Northwest. Proc. Natl. Acad. Sci. USA, 109, 11 619-11 623, doi:10.1073/pnas.1201083109.

Stensrud, D. J., R. L. Gall, S. L. Mullen, and K. W. Howard, 1995: Model climatology of the Mexican monsoon. J. Climate, 8, 1775-1793, doi:10.1175/1520-0442(1995)008<1775: MCOTMM $>2.0 . \mathrm{CO} ; 2$.

Stevenson, S., A. Timmermann, Y. Chikamoto, S. Langford, and P. DiNezio, 2015: Stochastically generated North American megadroughts. J. Climate, 28, 1865-1880, doi:10.1175/ JCLI-D-13-00689.1.

Swift, L. W., and H. T. Schreuder, 1981: Fitting daily precipitation amounts using the $S_{B}$ distribution. Mon. Wea. Rev., 109, 2535-2540, doi:10.1175/1520-0493(1981)109<2535:FDPAUT > 2.0.CO;2.

Thomson, D. J., 1982: Spectrum estimation and harmonic analysis. Proc. IEEE, 70, 1055-1096, doi:10.1109/PROC.1982.12433.

Tuttle, S., and G. S. Salvucci, 2016: Empirical evidence of contrasting soil moisture-precipitation feedbacks across the United States. Science, 352, 825-828, doi:10.1126/ science.aaa7185.

Vimont, D. J., D. S. Battisti, and A. C. Hirst, 2001: Footprinting: A seasonal connection between the tropics and mid-latitudes. Geophys. Res. Lett., 28, 3923-3926, doi:10.1029/ 2001 GL013435.

- J. M. Wallace, and D. S. Battisti, 2003: The seasonal footprinting mechanism in the Pacific: Implications for ENSO. J. Climate, 16, 2668-2675, doi:10.1175/1520-0442(2003)016<2668: TSFMIT $>2.0 . \mathrm{CO} ; 2$.

Wang, J., B. T. Anderson, and G. Salvucci, 2006: Stochastic modeling of daily summertime rainfall over the southwestern United States. Part I: Interannual variability. J. Hydrometeor., 7, 739-754, doi:10.1175/JHM518.1.

,$- \ldots$, and $\_, 2007$ : Stochastic modeling of daily summertime rainfall over the southwestern United States. Part II: Intraseasonal variability. J. Hydrometeor., 8, 938-951, doi:10.1175/JHM592.1.

Wang, S.-Y., R. R. Gillies, J. Jin, and L. E. Hipps, 2010: Coherence between the Great Salt Lake level and the Pacific quasidecadal oscillation. J. Climate, 23, 2161-2177, doi:10.1175/ 2009JCLI2979.1.

,,-- L. E. Hipps, and J. Jin, 2011: A transition-phase teleconnection of the Pacific quasi-decadal oscillation. Climate Dyn., 36, 681-693, doi:10.1007/s00382-009-0722-5.

— K. Hakala, R. R. Gillies, and W. J. Capehart, 2014: The Pacific quasi-decadal oscillation (QDO): An important precursor toward anticipating major flood events in the Missouri River basin? Geophys. Res. Lett., 41, 991-997, doi:10.1002/ 2013GL059042.

White, W. B., A. Gershunov, and J. Annis, 2008: Climatic influences on Midwest drought during the twentieth century. J. Climate, 21, 517-531, doi:10.1175/2007JCLI1465.1.

Wiles, G. C., R. D. D'Arrigo, and G. C. Jacoby, 1998: Gulf of Alaska atmosphere-ocean variability over recent centuries inferred from coastal tree-ring records. Climatic Change, 38, 289-306, doi:10.1023/A:1005396027562.

, - - D. Barclay, R. S. Wilson, S. K. Jarvis, L. Vargo, and D. Frank, 2014: Surface air temperature variability reconstructed with tree rings for the Gulf of Alaska over the past 1200 years. Holocene, 24, 198-208, doi:10.1177/ 0959683613516815.

Wilks, D. S., 1999: Interannual variability and extreme-value characteristics of several stochastic daily precipitation models. Agric. For. Meteor., 93, 153-169, doi:10.1016/ S0168-1923(98)00125-7.

Williams, C. N., R. S. Vose, D. R. Easterling, and M. J. Menne, 2006: United States Historical Climatology Network daily temperature, precipitation, and snow data. Carbon Dioxide Information Analysis Center, Oak Ridge National Laboratory. [Available online at http://gcmd.nasa.gov/records/ GCMD_CDIAC_NDP070.html.]

$\mathrm{Wu}$, S.-Y., 2015: Changing characteristics of precipitation for the contiguous United States. Climatic Change, 132, 677-692, doi:10.1007/s10584-015-1453-8.

Zheng, X., H. Nakamura, and J. A. Renwick, 2000: Potential predictability of seasonal means based on monthly time series of meteorological variables. J. Climate, 13, 2591-2604, doi:10.1175/ 1520-0442(2000)013<2591:PPOSMB > 2.0.CO;2. 